\title{
Improving Safety on Indonesian Fishing Fleet: A Case Study on Local Fishing Communities in East Java
}

\author{
I Putu Arta Wibawa ${ }^{1, a, *}$, and Richard W. Birmingham ${ }^{2}$ \\ ${ }^{I}$ Design and Construction Study Program Politeknik Perkapalan Negeri Surabaya, Surabaya \\ Indonesia \\ ${ }^{2}$ Marine, Offshore, and Subsea Technology Research Group, School of Engineering, Newcastle \\ University, Newcastle upon Tyne, United Kingdom \\ a.wibawaputuarta@gmail.com \\ *corresponding author
}

Keywords: $\quad$ Safety; Fishing Vessels; Fishers' Awareness

Abstract: The observations on the existing traditional fishing vessels and the in-depth interviews to local fishers in two fishing communities in East Java, Indonesia revealed that there is relatively low level of implementation of safety fishing practices on Indonesian fishing fleet. Improving health and safety working environment on Indonesian fishing boats, in order to support the application of appropriate safety fishing practices, can be addressed by improving local fishers' awareness on safety, adopting relevant standards and guidance for local fishers, and supporting local fishers in developing decent working environment on their fishing vessels.

\section{Introduction}

Fisheries have become the main livelihood for fishing communities along the Indonesian coastal line. The vast potential in fish resources coupled with the relatively low skill requirement to be a fisher in conjunction with challenges in finding a suitable job onshore are the main reasons for the significant numbers of people, coastal communities in particular, relying on fishing for their living. Based on the Indonesian Marines and Fisheries in Figures 2015, there were in the region of 2.2 million fishers along the Indonesian coastline [1]. These massive population of fishers operate more than 600 thousand fishing vessels [1], which are most of them are small fishing vessels, up to 3GT, with the relatively low level of technology employed on-board [2].

The reduced amount of fish stocks available in traditional fishing grounds in the last decade [3-5] has forced most local fishers in many fishing communities to fish further from their more common fishing grounds, and thus over longer round-trip durations. In addition to the increasing operational costs, fishing for longer periods and further afield can result in an escalation in the potential for risks that the fishers are confronted by during extended fishing periods and operations. With the existing physical conditions of local fishing vessels and the relatively low level of fishers' awareness in connection with safety at work, the increase in risks during their work could endanger fishers' lives. There are no official data related to fishing vessels accidents in Indonesia [6]; however, The People's Coalition for Fisheries Justice (KIARA) noted that the number of fishers who died at sea in one year 
is very high. KIARA claimed that in 2012 there were 186 fishers who died at sea, as many as 225 in 2013 and 210 people in 2014 [7].

Working on fishing vessels is one of the most hazardous of jobs in the world, particularly in adverse weathers. The only way to reduce the level of danger is by reducing the risks associated with the operation of the vessels. In addition to the actual design of the vessels, potential risks on-board are evidently influenced by fishers' awareness of the importance of establishing and maintaining a safe working regime and environment during their fishing trips.

This paper explores the existing condition of the traditional fishing vessels in Indonesia regarding the health and safety working environment on board. Case studies have been conducted in two fishing communities in East Java, Indonesia in order to have an overview about the implementation of safety practice on board of local fishing vessels. Moreover, the local fishers' awareness on safety fishing has been elicited. How it has affected their decision on complying with the regulations on safety fishing is presented, and any measures to develop better implementation of safety fishing are discussed in this paper.

\section{International Concerm on Safety Fishing Practices}

The fisheries sector, which provides employment for millions of people and sustains the livelihood of another hundred million people globally, has a significant role in ensuring food supply security and is an economic driver for many countries worldwide. The existence of this sector particularly in relation to the welfare of current and future generations is believed to be in a perilous situation if little or no effort is made to manage the sector responsibly and in sustainable ways.

Undertaking responsible fishing practices and developing a fishing vessel in a way that the vessel itself is sustainable, are among the efforts that must be undertaken with respect to achieving the sustainability of fisheries sector in the future. Concerning the criteria for sustainable fishing vessels, according to the Food and Agriculture Organisation (FAO), one of the main criteria can be with regards to the social aspect which is the safety of the fishing vessels [8]. Utne (2008) applied 7 criteria to assess the sustainability of Norwegian fishing vessels, based on the objectives of Norway's sustainable fisheries management. These attributes including risk of accidents during fishing trip, in addition to profitability, employment, fish quality, catch capacity, greenhouse (GHG) emissions and bycatch [9].

Both FAO and Utne (2008) put safety factor as one of the main criteria for sustainable fishing vessels. In fact, the safety aspect of the fishing practices has been the main issues in the world capture fisheries for the last few decades. The International Labor Organisation (ILO) estimated that 24,000 fatalities occur worldwide per year in fisheries [10]. The high fatality in fishing industry has put the three organisations within the United Nations Organisations: FAO, ILO, and IMO into an agreement to develop the global instrument on health and safety fishing as the guidance for every States that involved in fishing industries.

Few milestones for the safety standards on fishing vessels already in place are [10]: 1) The 1993 Torremolinos Protocol which is the substitution of the Torremolinos International Convention for the Safety of Fishing Vessels (1977). The Protocol applies to fishing vessels of $24 \mathrm{~m}$ in length and over, and addressed some safety requirements including improved life-saving appliances, satellite communication systems and other components of the global maritime distress and safety system (GMDSS); 2) The FAO/ILO/IMO Code of Safety for Fishermen and Fishing Vessels (2005) that consist of two parts. Part A applies to all fishing vessels concerning the health and safety practices on board. Part B applies specifically to decked fishing vessels of 24 meters in length and over and addresses safety and health requirements for the construction and equipment of fishing vessels; 3 ) The FAO/ILO/IMO Voluntary Guidelines for the Design, Construction and Equipment of Small 
Fishing Vessels (2005), which is applied for fishing vessels of 12 meters length up to 24 meters length; and 4) The FAO/ILO/IMO Safety Recommendations for Decked Fishing Vessels of Less than 12 meters in Length and Undecked Fishing Vessels in every size [11].

The adoption of the safety recommendation for decked/undecked fishing vessels of less than 12 meters in length was the answer for the concern on the population of fishing boats worldwide that is dominated by small fishing vessels up to 12 meters in length (L) both decked and undecked vessels. About two-thirds of total fishers in the world work on this size of fishing vessels [10]. Some important points from the recommendation for small fishing boats up to 12 meters in length [11] including any measures to prevent of seawater flooding into the compartments below the deck by ensuring the weathertightness of the deck openings and all access in bulkheads of enclosed superstructures, also by determining a minimum height of coamings for every deck openings on board. There are some recommendations as well to guarantee that fishers have decent conditions of work on board concerning to minimum requirements for work on board; conditions of service; accommodation; and occupational safety and health protection.

As the follow-up of those aforementioned instruments, it is the States responsibility to ensure that those international standards and recommendations are embedded in their national standard for safety requirements of their national fishing fleet. The FAO, through The Code of Conduct for Responsible Fisheries 1995, encourages every States involved in fishing industry should ensure that health and safety standards are adopted for everyone employed in fishing operations. Such standards should be not less than the minimum requirements of relevant international agreements on conditions of work and service on fishing vessels [12].

\section{Method}

Most of fishing boats in Indonesia are small fishing vessels up to 3 GT or less than 12 meters in length. Therefore, the FAO/IMO/ILO safety recommendation for decked fishing vessels of less than 12 meters in length can be applied as guidance for identifying level of implementation of the health and safety in Indonesia fishing vessels. In order to have an overview about the existing condition of traditional fishing vessels and moreover the fishers' awareness in term of safety, the field study has been conducted in two fishing communities in Indonesia: the Muncar village in eastern part of East Java and the Brondong village in northern part of East Java.

The methods that were applied to collect information from these two fishing communities were in-depth interviews to local fishers and field observation on local fishing vessels. The observation on local fishing vessels aimed at identifying health and safety practices on board, including the availability of safety equipment on traditional fishing boats. Furthermore, the in-depth interviews were conducted to understand the local fishers' awareness on the health and safety practice on their fishing boats.

For the in-depth interviews a total 53 of respondents were interviewed. Of these 28 respondents were local fishers in Brondong and 25 respondents were local fishers in Muncar. Utilising a series of open-ended questions, session were conducted in the following topic: local fishers' understanding on the risk of being a fisher; health and safety practices on board, including the availability of safety equipment on respondents' fishing boats; local fishers' willingness to provide safety equipment on their vessels; and respondents' understanding of the official regulations related to all aspects of fishing practices and the consequences of violating such regulations. In addition, Linkert Scale was applied to identify local fishers' interest in providing safety equipment on their fishing boats in the near future. The 1-5 point response scale was used to identify the fishers' willingness to provide safety equipment on their fishing boats with the level of enthusiasm being: (1) very low, (2) low, (3) moderate, (4) high, and (5) very high. 


\section{Result and Discussion}

\subsection{The condition of safety working environment on current fishing vessels}

The observations on local fishing boats regarding the implementation of health and safety on board identified the following conditions in few aspects of the local vessels:

\subsubsection{Accommodation}

There are no proper accommodation facilities available on local fishing vessels in two selected fishing communities. For instance, the traditional fishing boat in Brondong, called "Ijon-ijon", which is goes fishing for up to two weeks with about 10-25 fishers on board, only have a simple shelter approximately $2 \mathrm{~m} \times 3 \mathrm{~m}$, as seen in Fig.1. Most of accommodations on "Ijon-ijon" boats are not enclosed structure; therefore, it has no adequate protection against weather. The floor of the shelter, which is used as sleeping space, actually is the cover of engine casing in the form of moveable wood planks. Consequently, this crew space has no enough protection from the heat and the noise from the engine.

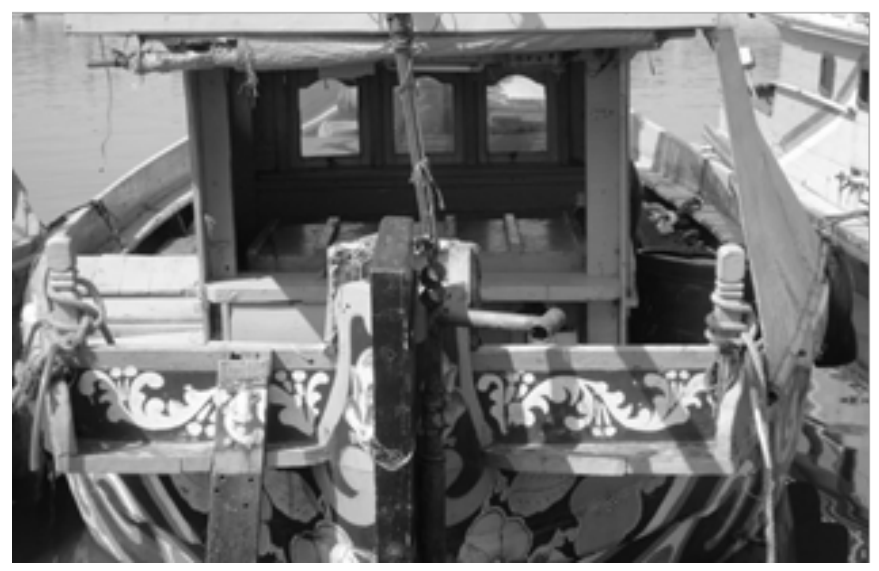

Figure 1: The accommodation space on "Ijon-ijon" Boat in Brondong (Photo by the Author)

The respondents in Muncar and Brondong all argue that most of their time will be spent actually catching fish; therefore, they believe that they do not need proper permanent accommodation onboard. In fact, in many local fishing boats, the 'cabin' used by the crew is a simple shelter with a tarpaulin as the roof.

The similar conditions can also be found for the cooking and sanitary facilities in the vessels operating in the two fishing communities. In Brondong, for example, the cooking facilities for fishing boats that go to sea for more than two weeks at a time is only a simple stove that is placed inside a wooden box to avoid the wind and positioned in an open space on deck without any shelter. 


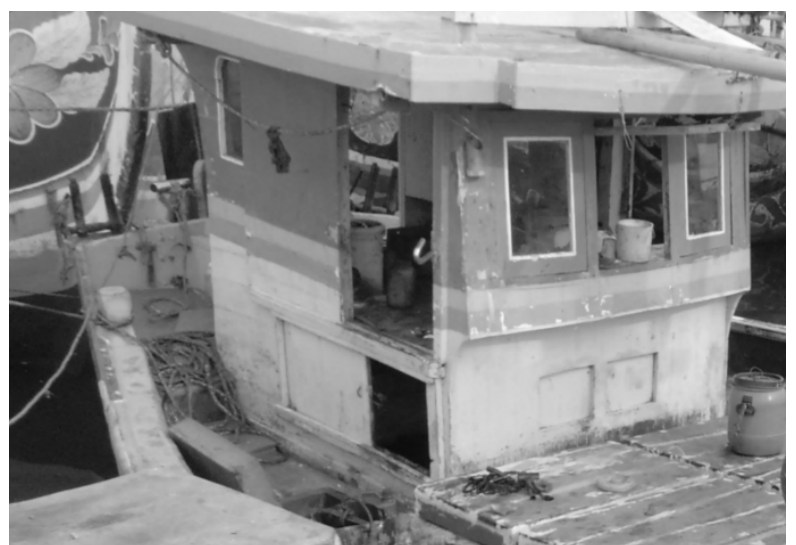

Figure 2: The access to engine room below the sleeping space for crew (Photo by the Author)

With regard to sanitary facilities, none of the fishing vessels in the two selected fishing communities have sanitary facilities on-board, even for vessels that go fishing for more than two weeks. It should also be mentioned that the respondents believe that a proper toilet facilities are not required on board. They argue that if they need to go to the toilet during their fishing trip they can simply use the side of the deck as a temporary natural toilet. Obviously it is an open space and the crew just hold on to the bulwarks or other structures at the deck side.

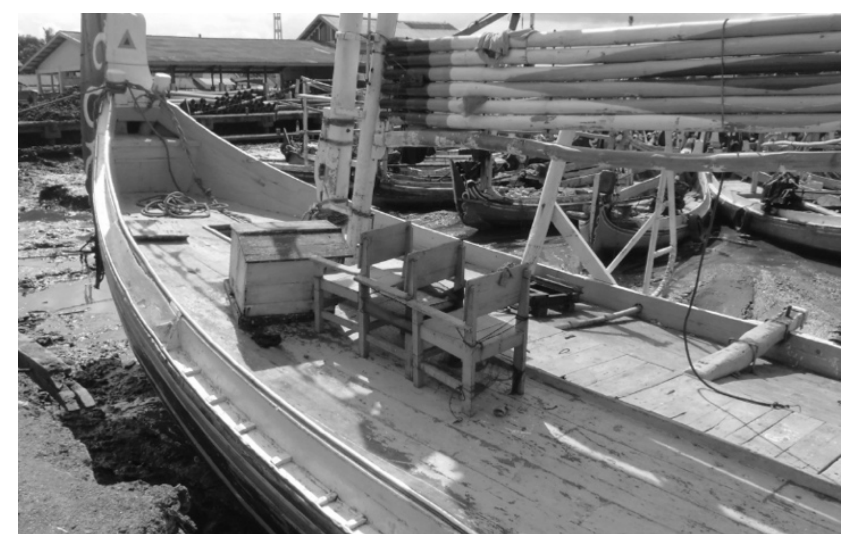

Fig. 3. The low bulwark and hatchway on Slerek fishing boat, Muncar (Photo by the Author)

\subsubsection{Deck Opening, Doors and Bulwarks}

The non-standard deck openings is others concerns regarding the safety of the local fishing vessels, in particular related to the risk of seawater flooding into the compartments below the deck during severe sea condition that eventually endanger the safety of the vessels itself.

The observation on local fishing boats showed that local fishers tend to avoid the high coaming for deck openings for practical reason. As seen in Fig.2, the height of coaming for access leading to engine room from weather deck is only about $150 \mathrm{~mm}$ height. Moreover, the door that is installed for this access is a simple sliding door without any arrangement to ensure the weathertightness of this access.

Concerning the hatch coaming for fish hold, the local fishers claimed that the coaming with 460 $\mathrm{mm}$ height, as required by the Indonesian Classification Bureau for fishing vessel [13], will distract their fishing activities on deck especially during the deploying and hauling the net. Moreover, according to the fishers, their nets can easily become stuck in the hatchway if it is too high. 
According to FAO/ILO/IMO recommendations, a lower hatch coaming height can be implemented as long as the water-tightness of the hatch cover can be ensured [11]. However, by considering the local fishers' awareness of safety on-board, the idea to employ lower hatchway coamings with a watertight cover system could be incorrectly maintained by local fishers.

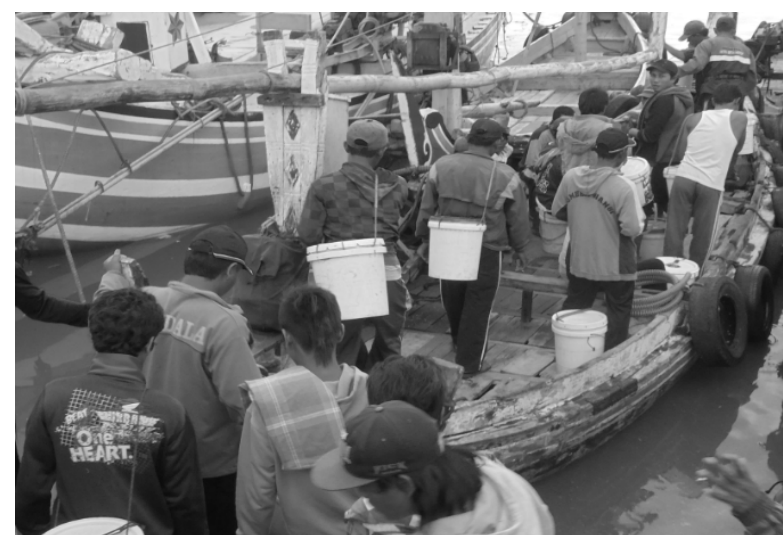

Figure 4: The bucket as substitution for life-saving appliances in Muncar (Photo by the Author)

Concerning the height of the bulwarks structure, the local fishers prefer to have lower bulwarks on their boats, as seen in Fig. 3 given that the standard bulwark, which has a minimum height of 1 meter [11], can disturb the flow of fishing activities on deck and therefore considered to be inefficient according to local fishers.

\subsubsection{Safety Equipment on Board}

The survey on local fishing boats in Muncar and Brondong also found that there is problem with the availability of safety equipment on board.

Almost none of the fishing vessels in Muncar have standard life jackets and lifebuoys on-board. Although a few respondents in Brondong did say that they do have those two types of safety equipment, however the quantity of their life jackets is considerably less than the number of crew onboard. Moreover, local fishers argue that the conventional safety equipment could be substituted for by other objects available on their fishing vessels. For example, fishers in Muncar argued that they can use the plastic buckets that are normally used for meal and cloths storage as a substitute for lifesaving appliances, as seen in Fig. 4

An additional significant issue is local fishers' willingness to provide fire extinguishers on-board. There is a relatively high risk of fire on-board, particularly when considering the fishers' habit of smoking during their fishing activities and how the local fishers frequently treat their engine's fuel system. Respondents argue that they do not need to worry if a fire occurs on-board, as there is a significant amount of water surrounding the boat.

Concerning the navigational devices on-board, many fishing vessels in Brondong have been equipped with Global Positioning System (GPS) equipment in order to help fishers to navigate their vessels. Respondents stated that they had gained a considerable advantage by using GPS on-board. It was interesting to ascertain from one of the respondents in Brondong, a 35 year old skipper, who confessed that he really depends on the GPS to guide him home, as he does not have the skill to navigate in a traditional manner using astronomy and other natural signs, like his ancestors had done.

In contrast with the fishers in Brondong, fishers in Muncar have never operated any navigation devices on-board. They argued that their fishing ground is quite close to land and that they can still use any known site on land in order to locate their position and to navigate back to port. 
In term of communication devices on-board, most fishing vessels in the two fishing communities prefer to use mobile phones to communicate with their home port, although the use of mobile phones for communication on-board local fishing vessels does not always work properly especially when well out at sea. According to respondents, their mobile phones only work properly if the vessel is reasonably close to the islands that support the network coverage.

A further aspect is that of on-board navigation lights which are not common in all two fishing communities. According to respondents in Brondong, accidents frequently happened at sea, in which local traditional fishing boats were accidentally struck by large ships during the night, predominantly coal bulk carriers, because most of the boats are not equipped with the navigational lights. Moreover, none of the fishing boats in these two communities have a simple radar reflector, which is actually affordable for local fishers and effective enough to avoid the collision with large vessels.

\subsection{The Local Fisher's Awareness on Safety Fishing Practices}

Based on the interviews, the local fishers in the two selected fishing communities are very conscious of the risks that they confront being fishers. They fully understand that maximum risk of their job could endanger their lives. It can be revealed from the anxiety they demonstrated in relation to their sons possibly following in their steps and themselves becoming fishers. However, health and safety practices on the fishing vessels have not yet become routine or second nature for local fishers. In contrast to local fishers understanding in relation to the risks associated with their job, their willingness to use various items of safety equipment and applying safety standards, to avoid for example potential injuries, is still very low.

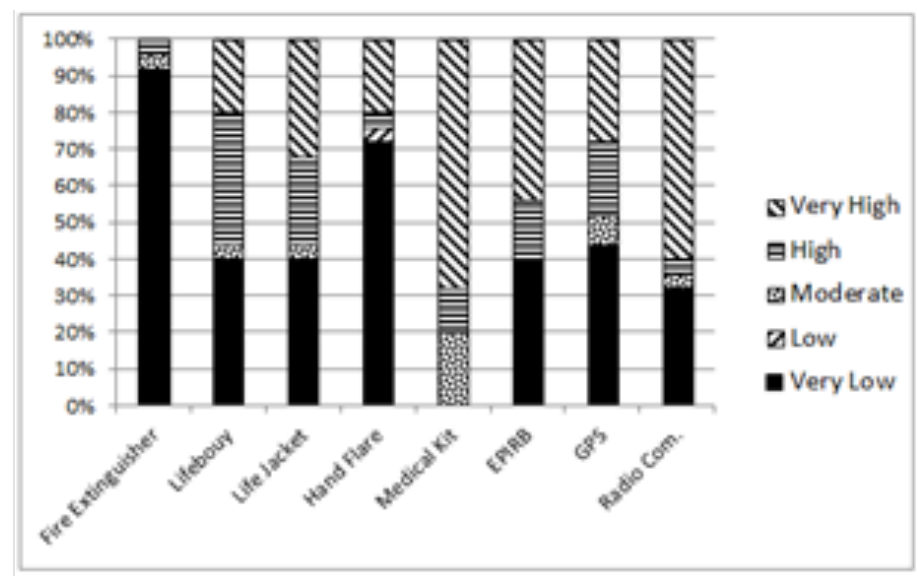

Figure 5: Level of Muncar fishers' willingness to provide safety equipment

In order to have further understanding on local fishers' awareness on safety practices, one part of discussion during in-depth interview was related to the fishers' interest to equip their fishing vessels with proper safety equipment. The results of the respondents' responses on this part of indepth interview are presented in the form of bar charts in Figure 5 and Figure 6. 


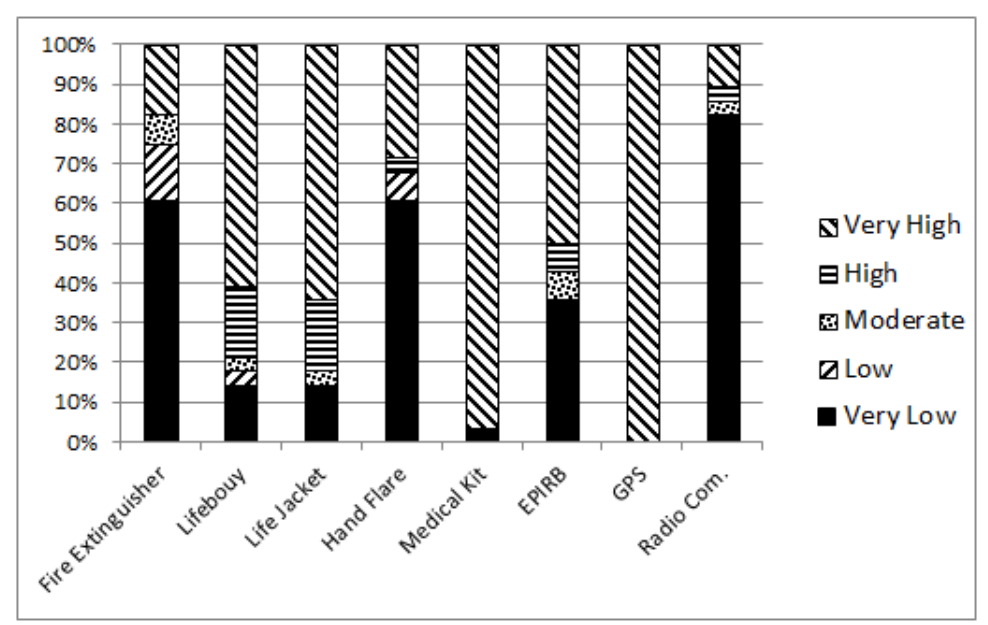

Figure 6: Level of Brondong fishers' willingness to provide safety equipment on board

These two figures show that there is still lack of local fishers' interest to equip their fishing boat with standard safety equipment, although it is compulsory to be provided on board, as seen in Table 1. Even for some equipment, such as fire extinguisher, the level of local fishers' willingness to provide this equipment is significantly low. Moreover, although the bar charts demonstrated high local fishers' interest for some safety equipment, nevertheless, the real condition on the local fishing boats regarding the availability of these safety equipment showed in contrast.

Additionally, based on the interviews, it would appear that the local fishers' collective awareness concerning the regulation of the fisheries in the two fishing communities is quite low. Most respondents are not fully aware of any regulations that apply to their fishing boats and to their fishing activities. Moreover, the fishers apparently feel burdened if given any responsibility over and above fishing, such as obtaining port clearance before leaving the port

In addition, and for mainly economic reasons, the respondents argued that a number of the regulations are quite difficult to fulfil, an example being the requirement to provide safety equipment on-board in order to obtain port clearance. Based on the interviews, the fishers are reluctant to purchase safety equipment, seeing that it is not considered to be important enough for them. Furthermore, providing the life jackets, life buoys and additional safety equipment means further spending which is considered to be burdensome by the local fishers.

Based on the interviews, the enforcement of the port clearance regulation is one of the greatest challenges for the administrators at the local fishing ports and local fisheries departments. According to the national regulations regarding fishing activities, each fishing boat must obtain approval from the harbour master, in the form of port clearance, immediately prior to leaving the port. To gain the port clearance certificate, a fishing vessel should pass an inspection by the fisheries inspectors, related to the availability and the condition of the equipment on-board, as listed in Table 1. 
Table 1. Point of inspections for issuing Port Clearance in Indonesian fishing harbour

\begin{tabular}{|l|l|}
\hline No & \multicolumn{1}{|c|}{ Point of Inspections } \\
\hline 1 & Boat certificates and fishing licences \\
\hline 2 & Crew certificates \\
\hline 3 & Number of crew in accordance with the fishing licences \\
\hline 4 & Safety equipment complies with the requirements \\
\hline 5 & Fishing gear in accordance with the fishing licences \\
\hline 6 & Navigation equipment complies with the requirements \\
\hline 7 & $\begin{array}{l}\text { The engine and its equipment are in good condition and fulfil the } \\
\text { requirements }\end{array}$ \\
\hline 8 & All bilge pumps in good condition and work properly \\
\hline 9 & Radio communication complies with the requirements \\
\hline 10 & The devices tused for pollution prevention work correctly \\
\hline 11 & The dranght of the boat does not surpass the maximum load line \\
\hline 12 & The boat has good stability to sail \\
\hline 13 & The tonnage measurement number is marked accurately \\
\hline 14 & The freeboard mark is marked accurately \\
\hline 15 & The fire extinguishers comply with the requirements. \\
\hline
\end{tabular}

However, the strict enforcement of several regulations, particularly for artisanal fisheries, is believed to be causing a few social problems and creating a degree of anxiety among the local fishers concerning the continuity of their income. The harbour master in one of these two communities acknowledged that if he was strict with enforcing all of the requirements, as listed in Table I, and only issued port clearance when compliant with listed requirements, there would be no fishing boats going to sea, since there are no fishing vessels with standard safety equipment on-board. Therefore, the enforcement of this regulation has become applied in a more flexible way for local fishing boats.

\subsection{Measures to Improve Safety Working Environment}

Based on the observation on local fishing vessels and the result of interviews to local fishers in two fishing communities, the problems that need to be overcome in order to improve the implementation of safety working environment on Indonesian fishing vessels are related to: the condition of current fishing boats regarding the safety aspects on board; the fishers' awareness and responsibility to implement safety fishing practices; the availability and the enforcement of national regulation about safety fishing practices.

The current Indonesian government policy to build thousands of fishing vessels, which are granted to group of fishers in many fishing communities in Indonesia, should be followed by the improvement of safety working environment of the new fishing vessels. The granted vessels with better safety working environment on board and completed with standard safety equipment can possibly influence the fishing communities where the new vessels will be operated. Moreover, since the economic reason is the obstacles for local fishers to provide standard safety equipment on their fishing boats, the government can improve the availability of this safety equipment on existing fishing vessels by similar scheme with the new boat programme that are granted to local fishers.

The minimal level of fishers' awareness on safety practices is believed also caused by the low formal education background of local fishers. Based on the interviews, most of the fishers started their job as a fisher at a young age, typically just after finishing primary school at 12 years old. And their competencies in fishing practices were obtained from their elders and through the actual experiences. There is no specific training to prepare the young fishers about fishing responsibly and safely before they start as a fisher. This low level of education background also affected fishers' acceptance to any improvement on their fishing vessels, including, for instance, to new type of technology related to navigations and communication devices to support safety fishing practices. In 
order to improve local fisher' awareness in term of safety fishing practices, as suggested by the Code of Conduct for Responsible Fisheries, the government should enhance, through education and training programmes, the education and skills of fishers and, where appropriate, their professional qualifications. Providing better and comprehensive safety equipment on board will be ineffective without any improvement being imparted in the crews' knowledge and in their willingness to use such equipment, and also their accountability in implementing health and safety standards in their own working environment.

Improving fishers' awareness on safety practices also can be developed through their families and their fishing communities. The development of safety culture in fishers' families can be started from very young ages in fishing communities through safety education at school. With strong safety culture from the family, it can encourage the local fishers in developing their awareness on safety fishing practices.

With regard to national regulations, there is currently a problem in the availability of comprehensive regulations related specifically to fishing boats. There is no specific national regulation or standard concerned with the safety of fishing vessels, especially for small fishing vessels that are up to 12 metres in length. Therefore the ratification and adoption of relevant standards and the development of more applicable guidance for fishers is crucial for Indonesian fishing fleet. From the government point of view, it is important to develop national standard on safety fishing that consider the condition of Indonesian fishers, and also the boat yards that will build the vessels. There should be a certain objective that is targeted by the standard, but still allows the fishers and boatyards to achieve this objective in whatever way is most possible or economical [14]. Furthermore, the enforcement of regulation related to safety fishing practices in Indonesia need to be imposed gradually and should be socialised continuously so the fishers more aware about the regulation related to their fishing boats.

\section{Conclusions}

The issues related to ensuring adequate health and safety in the working environment is a challenge that is relatively difficult to overcome in Indonesian fisheries sector. The lack of fishers' awareness of health and safety issues is the main problem in implementing and creating a robust health and safety operating environment on-board vessels and throughout each fishing trip. The empowerment of local fishers and their communities by providing people with a better education and by improving their professional competencies on fishing practices are the most appropriate ways to develop their personal role in achieving responsible fisheries including in implementing safety fishing practices.

The Indonesian government should give more attention on the implementation of safety fishing practices on board fishing vessels. The adoption of relevant standards and the development of effective guidelines, in particular for traditional fishers, are the main requirement for developing better safety fishing practices on Indonesian fishing fleet.

Other measures to develop better safety fishing practices on Indonesian fishing fleet should be conducted continuously that consider the current condition of local fishing vessels and the condition of fishers themselves in term of economy and education background. For instance, government can provide soft loan for fishers, or in other scheme of support that can help fishers in providing safety equipment for their fishing boats The HFACS for Ship Collision is applicable to the marine collision in Indonesia. 


\section{References}

[1] MMAF, "Marine and Fisheries in Figures 2015”, Indonesian Ministry of Marine Affairs and Fisheries (MMAF), 2015.

[2] MMAF, “Ministerial Regulation No.45/PERMEN-KP/2015: Strategic plan for year 2015 - 2019 (in Indonesian). Indonesian Ministry of Marine Affairs and Fisheries (MMAF), 2015.

[3] Ainsworth, C.H., Pitcher, T.J. and Rotinsulu, C., "Evidence of fishery depletions and shifting cognitive baselines in Eastern Indonesia”, Biological Conservation, 141(3), pp. 848-859, 2008.

[4] Heazle, M. and Butcher, J.G.,"Fisheries depletion and the state in Indonesia: Towards a regional regulatory regime”, Marine Policy, 31(3), pp. 276-286, 2007.

[5] Patlis, J.,"Indonesia's new fisheries law: will it encourage sustainable management or exacerbate overexploitation?", Bulletin of Indonesian Economic Studies, Vol.43(2), pp. 201-226, 2007.

[6] Suwardjo, D., Haluan, J., Jaya, I. and Poernomo, S.a.H., "Fishing vessel safety from national and international regulations point of view”, Jurnal Teknologi Perikanan dan Kelautan, Vol.1(1), pp. 1-13, 2010.

[7] Grahadyarini, B.L., "Develop self-sufficient fishers", Available at: http://www.kiara.or.id/memandirikan-nelayan/, 2015 .

[8] Garcia, S., Indicators for sustainable development of fisheries”, 2nd World Fisheries Congress. Brisbane, Australia. Available at: http://www.fao.org/docrep/w4745e/w4745e0f.htm, 1996.

[9] Utne, I.B., "Acceptable sustainability in the fishing fleet", Marine Policy, 32(3), pp. 475-482, 2008

[10] Gudmundsson, A., "International instrument on the safety of fishing vessels and fishermen", Bay of Bengal News, March 2006.

[11] FAO/ILO/IMO,"Safety recommendations for decked fishing vessels of less than 12 metres in length and undecked fishing vessels", FAO, Rome, 2012

[12] FAO," Code of Conduct for Responsible Fisheries", Food and Agriculture Organizations (FAO), Rome, 1995.

[13] BKI, "Guidance for FRP and wooden fishing vessel up to 24 m”, Biro Klasifikasi Indonesia (BKI), 2015.

[14] Birmingham, R.W. and Sampson, R. (2001) 'Safety and sustainability in the fishing industry: a design conflict', International Conference on Small Craft Safety. London, UK, 22 - 23 May 2001. RINA 